\title{
Enhanced performance of a Bi-modified graphite felt as the positive electrode of a vanadium redox flow battery
}

Z. González, A. Sánchez, C. Blanco, M. Granda, R. Menéndez, R. Santamaría* Instituto Nacional del Carbón, CSIC, P.V. Box 73, 33080-Oviedo, Spain

\begin{abstract}
Graphite felt modified with nanodispersed bismuth was studied as electrode in the positive half-cell of a vanadium redox flow battery (VRFB). The felt was easily modified by immersion in a $\mathrm{Bi}_{2} \mathrm{O}_{3}$ solution followed by thermal reduction at $450^{\circ} \mathrm{C}$ in air. Despite the low metal content (1 at. \%), the Bi-modified felt showed an excellent electrochemical performance (at $1 \mathrm{mVs}^{-1}$ ) in terms of anodic and cathodic peak current densities (21 and $17 \mathrm{~mA} / \mathrm{cm}^{2}$, respectively), reversibility $\left(\Delta E_{p}=0.050 \mathrm{~V}\right)$ and overpotential for the $\mathrm{V}(\mathrm{IV}) / \mathrm{V}(\mathrm{V})$ redox reactions. Furhtermore, repetitive cyclic voltammetry measurements, at various scan rates, evidenced the long term stability of this material. These results demonstrate that bismuth nanoparticles on the carbon surface act as stable active sites to promote these reactions, and represent a significant step forward towards the development of outstanding electrode materials for VRFB.
\end{abstract}

Key words: vanadium redox flow battery, graphite felt, Bi-modified electrode, active surface area, electrical conductivity, cyclic voltammetry.

\footnotetext{
* Corresponding author: Ricardo Santamaría (iqqui@incar.csic.es), fax.: +34 985297662
} 


\section{Introduction}

Redox flow batteries (RFBs) have attracted a great deal of interest in recent years because they appear to be promising electrochemical energy storage systems [1]. Unlike other types of batteries, the electrodes in RFBs do not directly act as charge storage elements. Instead, the energy is stored and converted through chemical changes into electroactive species dissolved in two liquid solutions. Thus, this kind of battery possesses advantages such as long life, flexible design, high energy efficiency $(\sim 70 \%)$, as well as low maintenance cost [2].

The vanadium redox flow battery (VRFB) has the additional advantage of employing the same metal in both half-cells $(\mathrm{V}(\mathrm{IV}) / \mathrm{V}(\mathrm{V})$ as the positive electrolyte and $\mathrm{V}(\mathrm{II}) / \mathrm{V}(\mathrm{III})$ as the negative one) thereby eliminating any possibility of cross-over contamination [3].

Graphite felts (GFs) are commonly used as electrode materials in VRFBs due to their wide operation potential range, stability as anode and cathode, high surface area and availability at a reasonable cost [4-9]. However, the low electrochemical activity of commercial GFs, due to poor kinetics and reversibility, limits their use as active electrode material. Consequently, a great deal of attention has been directed towards the modification of these carbon materials in order to improve their electrochemical performance. The most widely used treatments are thermal activation [3], electrochemical oxidation [4] or treatment with sulfuric acid [7]. Their main objective is to introduce oxygenated functional groups onto the fibre surface in order to enhance 
wettability towards the electrolyte and to increase the number of active sites for $\mathrm{V}(\mathrm{IV}) / \mathrm{V}(\mathrm{V})$ redox reactions.

In recent years, the deposition of metals on the surface of GFs has been used to greatly enhance their electrochemical performance, mainly through the improvement of electrical conductivity. The first studies proposed metallization by impregnation or ion-exchange with solutions containing $\mathrm{Pt}^{4+}, \mathrm{Pd}^{2+}, \mathrm{Au}^{4+}$, $\mathrm{Mn}^{2+}, \mathrm{Te}^{4+}, \mathrm{In}^{3+}$ or $\mathrm{Ir}^{3+}$. The best electro-catalytic behaviour for vanadium redox couples in a $\mathrm{H}_{2} \mathrm{SO}_{4}$ solution was obtained using materials modified with Ir [10]. Other studies investigated the distribution of metals ( $\mathrm{Sb}, \mathrm{As}, \mathrm{Se}, \mathrm{Ir}$ ) or alloys $(\mathrm{PtRu})$ on the surface of carbon materials after they had been subjected to different treatments such as thermal reduction [11] or electrodeposition [12]. In the former, the carbon material is immersed in a solution containing the metallic ions and then it is thermally treated in air at high temperatures. In the latter the metal is electrodeposited from a galvanic bath onto the surface of the carbon material through the application of a given current. In both cases the main objective is to reduce the metal load in the electrodes.

This paper investigates the electrochemical behaviour of a GF modified with thermally reduced bismuth as positive electrode in a VRFB. Although this metal has been successfully used to measure concentrations of trace metals [13-15], as an alternative to commonly used toxic mercury, this is the first time that $\mathrm{Bi}$ has been applied to VRFB. Additional advantages of the research carried out here are the low cost of bismuth, compared to other metals like Pt, Au or Ir, and the low metal load required. 


\section{Experimental}

\subsection{Electrode material}

Rayon-based graphite felt (Carbone Lorraine, France) was used as raw material. Modification with bismuth was performed by immersing disks (12 mm in diameter and $3 \mathrm{~mm}$ thick) of the as-received felt (ARGF) into a saturated solution of $\mathrm{Bi}_{2} \mathrm{O}_{3}$ (nanopowder, $90-210 \mathrm{~nm}$ particle size, Sigma Aldrich) in 0.01 $\mathrm{M} \mathrm{HCl}$ (ACS reagent, $37 \%$, Sigma Aldrich) under vacuum for $3 \mathrm{~h}$, followed by thermal treatment in air at $450^{\circ} \mathrm{C}$ for $3 \mathrm{~h}$. The resultant samples were labelled as BiGF. Additional samples were obtained by directly treating the GF at $450^{\circ} \mathrm{C}$ for $3 \mathrm{~h}$ without immersing it in the Bi-solution. These samples were labelled as TTGF and were used for comparison purposes.

\subsection{Physicochemical characterization}

A general survey of the major elements present on the surface of the graphite felt samples was performed by X-ray photoelectron spectroscopy (XPS), using a VG-Microtech Multilab 3000 spectrometer (SPECS, Germany) equipped with a hemispherical electron analyser and a $\mathrm{Mg} \mathrm{K \alpha}(h v=1253.6 \mathrm{eV}) \mathrm{X}$-ray source. The apparent BET surface area of the graphite felts was determined by applying the BET equation to the nitrogen adsorption isotherms obtained at $77 \mathrm{k}$ on a Micromeritics ASAP $^{\circledR} 2420$ instrument.

The surface morphology of the fibres in the felts was studied by scanning electron microscopy (SEM) using a FEl model Quanta FEG 650 instrument. A backscattering detector was used to study the metal distribution in the Bimodified samples. 


\subsection{Electrochemical characterization}

Cyclic voltammetry experiments were performed in a Swagelok ${ }^{\circledR}$ type threeelectrode cell at room temperature. The cell consisted of the sample of graphite felt as the working electrode, a $\mathrm{Hg} / \mathrm{Hg}_{2} \mathrm{SO}_{4}$ as the reference electrode and a platinum gauze as the counter electrode. All the potentials in this study are quoted with reference to $\mathrm{Hg} / \mathrm{Hg}_{2} \mathrm{SO}_{4}$ (i.e, $0.65 \mathrm{~V}$ vs. ENH) unless otherwise stated. The positive electrolyte consisted of a solution of $0.5 \mathrm{M} \mathrm{VOSO}_{4}$ (Sigma Aldrich) in $1.0 \mathrm{M} \mathrm{H}_{2} \mathrm{SO}_{4}$ (VWR International). Electrochemical measurements were performed on a Biologic VMP Multichannel Potentiostat. The potential sweeps always started from the open circuit potential (OCP) and the initial scan direction was positive. The scan rate was varied from 1 to $20 \mathrm{mVs}^{-1}$ and 100 cycles were registered at each one to evaluate the long term stability of the electrode materials under study.

\section{Results and discussion}

\subsection{Physicochemical characterization}

The major elements detected in all three samples, as determined by XPS, were carbon and oxygen. The atomic oxygen content on the surface increased slightly after thermal treatment in air (from $6.93 \%$ for ARGF to $8.39 \%$ for TTGF), as a result of a slight oxidation of the surface of the fibres. It is well known that a greater number of oxygenated surface functional groups increase the wettability of the felt which in turn contributes to a better electrochemical performance [12]. BiGF contains $1.09 \%$ bismuth, all of which is in elemental 
form (XPS binding energy $157.5 \mathrm{eV}$ ). Additionally, during the treatment applied to incorporate bismuth, the oxygen content increases significantly, reaching $11.52 \%$.

SEM images (Figure 1) show that the thermal treatment does not cause any visible change in the morphology of the fibres [5]. However, BiGF presents a high concentration of defects or holes. In fact, the BET apparent surface area increased from $0.92 \mathrm{~m}^{2} / \mathrm{g}$ for TTGF to $3.36 \mathrm{~m}^{2} / \mathrm{g}$ for BiGF. As illustrated in Figure 1 (d), Bi nanoparticles (size $\sim 35-50 \mathrm{~nm}$ ) are present on the fibre surface, mainly at the edges of the holes described above. This evidences the relevant role that bismuth plays as catalyst of fibre oxidation during thermal treatment in air.

\subsection{Electrochemical performance}

The cyclic voltammograms of the $\mathrm{V}(\mathrm{IV}) / \mathrm{V}(\mathrm{V})$ redox couple, measured at a scan rate of $1 \mathrm{mVs}^{-1}$ on the GF samples, are shown in Figure 2. The three samples exhibit an anodic peak associated with the oxidation of $\mathrm{V}(\mathrm{IV})$ to $\mathrm{V}(\mathrm{V})$, and a cathodic one associated with the reverse reaction. However, there are significant differences in relation with the values of the peak potentials and current densities (Table 1), which are indicative of differences in electrochemical performance. In ARGF, the peak potential separation $\left(\Delta E_{p}\right)$ of $0.31 \mathrm{~V}$ for the $\mathrm{V}(\mathrm{IV}) / \mathrm{V}(\mathrm{V})$ redox couple indicates that the reaction is electrochemically irreversible on this type of electrode. TTGF exhibits a better electrochemical activity, as the corresponding voltammogram shows an increase in peak current densities and a decrease in the $\Delta E_{p}$ value $(0.22 \mathrm{~V})$, 
indicating that in such an electrode the electrochemical reaction is a quasireversible process. This improved performance could be ascribed to the increase in wettability of the GF sample after the thermal treatment and to the elimination of fibre sizing as a result of which a larger active surface area is exposed.

However, the best results are obtained for BiGF. As can be seen in Fig. 2, this electrode exhibits the highest anodic and cathodic peak current densities and the lowest $\Delta \mathrm{E}_{\mathrm{p}}$ value $(0.05 \mathrm{~V})$, reflecting the huge improvement in electrochemical activity towards the $\mathrm{V}(\mathrm{IV}) / \mathrm{V}(\mathrm{V})$ redox reactions. Furthermore, repetitive CVs were performed (100 scans at $1 \mathrm{mV} / \mathrm{s}$, Figure 2) without observing any significant changes in the current density of peak potential values. This can be taken as an indication of the electrodes stability.

These higher values of $j_{p, a}$ and $j_{p, c}$, together with the reversibility condition described aboved, evidence that the BiGF electrode is the most appropriate material over the potential range studied. It is also worth pointing out that the better electrochemical performance displayed by the modified felt is achieved using only a low concentration of Bi nanoparticles on the surface of the fibers $(\sim 1 \%)$. These act as active sites, increasing the electrical conductivity of the sample and facilitating the electron transfer associated with the redox processes studied. These results are comparable to the best ones previously published, which were obtained using $99 \%$ of Ir on the GF surface [10].

In order to compare the kinetics of the $\mathrm{V}(\mathrm{IV}) / \mathrm{V}(\mathrm{V})$ redox reactions on the different electrodes, cyclic voltammograms were recorded at various scan rates (Figure 3). In all three electrodes, the $\Delta E_{p}$ value increases with the scan rate (from 1 to $20 \mathrm{mVs}^{-1}$ ), to the extent that on ARGF and TTGF samples, at scan 
rates higher than $1 \mathrm{mVs}^{-1}$ the cathodic peak was not developed during the reverse scan inside the potential range tested. These higher overpotentials required for the oxidation/reduction reactions could be explained taking into account the different polarization of the electrodes [16]. The polarization of BiGF is reduced significantly in comparison to that of ARGF and TTFG, due to the better electrical conductivity reached after the deposition of the metallic bismuth nanoparticles, which highly improves the charge transfer on the electrode/electrolyte interface. Furthermore, the linear relationship $\left(R^{2}=0.9998\right)$ between the anodic peak currents and the square root of the scan rate observed on BiGF indicates that the oxidation of the $\mathrm{V}(\mathrm{IV})$ specie might be only limited by its transport in the electrolyte in the range of scan rates tested [17], while on ARGF and TTGF this redox reaction is limited by charge transfer up to $2 \mathrm{mVs}^{-1}$ and has a mixed control (charge transfer/ionic transport in the electrolyte) at higher scan rates (up to $20 \mathrm{mVs}^{-1}$ ).

Simultaneously to the kinetic study, the stability test of the BiGF was completed making repetitive cyclic voltammograms (100 cycles) at each scan rate. No changes in the peak potentials and/or current densities values measured at each scan rate were observed, thus confirming the long term stability of this electrode.

\section{Conclusions}

Graphite felt modified with $1 \%$ nanodispersed bismuth exhibited an outstanding performance as positive electrode for a vanadium redox flow battery. It showed not only an excellent electrochemical performance in terms of anodic and cathodic peak current densities (21 and $17 \mathrm{~mA} / \mathrm{cm}^{2}$, respectively), reversibility 
$\left(\Delta E_{p}=0.050 \mathrm{~V}\right)$ and overpotential for the $\mathrm{V}(\mathrm{IV}) / \mathrm{V}(\mathrm{V})$ redox reactions, but also long term stability. These results demonstrate that the dispersion of bismuth nanoparticles on the carbon surface creates excellent stable active sites to promote these reactions and represents a significant step forward towards the development of VRFB electrode materials with high energy storage efficiency.

\section{Acknowledgment}

The authors thank MICINN (Project PSE-120000-2009-5), FICYT (Project PC10-35) and Hidroeléctrica del Cantábrico S.A. for their financial support.

\section{References}

[1] C. Ponce de León, A. Frías-Ferrer, J. González-García, D.A. Szánto, F.C. Walsh, J. of Power Sources 160 (2006) 716.

[2] Q. Liu, A. Sleightholme, A. Shinkle, Y. Li, L.T. Thompson, Electrochem. Commun. 11 (2009) 2312.

[3] M. Rychcik, M. Skyllas-Kazacos, J. of Power Sources 19 (1987) 45.

[4] S. Zhong, C. Padeste, M. Kazacos, M. Skyllas-Kazacos, J. of Power Sources 45 (1993) 29.

[5] B. Sun, M. Skyllas-Kazacos, Electrochim. Acta 37 (1992) 1253.

[6] X. Li, K. Huang, S. Liu, N. Tan, L. Chen, Trans. Nonferrous Met. Soc. China 17 (2007) 195.

[7] B. Sun, M. Skyllas-Kazacos, Electrochim. Acta 37 (1992) 2459.

[8] B. Sun, M. Skyllas-Kazacos, Electrochim. Acta 36 (1991) 513.

[9] L. Yue, W. Li, F. Sun. L. Zhao, L. Xing, Carbon 48 (2010) 3079.

[10] W. H. Wang, X.D. Wang, Electrochim. Acta 52 (2007) 6755. 
[11] E. Bulska, W. Jedral, E. Kopysc, H.M. Ortner, S. Flege, Spectrochim. Acta Part B 57 (2002) 2017.

[12] Z.D. Wei, S.H. Chan, J. of Electroanal. Chem. 569 (2004) 23.

[13] S. B. Hocevar, I. Svancara, K. Vytras , B. Ogorevc, Electrochim. Acta 51 (2005) 706.

[14] G. H. Hwang, W. K. Han, J.S. Park, S.G. Kang, Sens. and Act. B 135 (2008) 309.

[15] F. Arduini, J. Quintana Calvo, A. Amine, G. Palleschi, D. Moscone, Trends in Anal. Chem. 29 (2010) 1295.

[16] W. Li, J. Liu, C. Yan, Electrochim. Acta, 56 (2011) 5290.

[17] J. H. Kim. K.J. Kim, M.S. Park, N.J. Lee, U. Hwang, H. Kim, Y.J. Kim, Electrochem, Commun, (2011), doi: 10.1016/j.elecom.2011.06.022 
Table 1. Electrochemical parameters obtained from the CV curves (at $1 \mathrm{mVs}^{-1}$ ) for $\mathrm{V}(\mathrm{IV}) / \mathrm{V}(\mathrm{V})$ on the graphite felt samples tested.

\begin{tabular}{cccccc} 
& \multicolumn{2}{c}{ Anodic peak $^{(a)}$} & \multicolumn{2}{c}{ Cathodic peak $^{(\mathbf{b})}$} & \\
\cline { 2 - 5 } SAMPLE & $\mathrm{j}_{\mathrm{pa}}\left(\mathbf{m A} / \mathbf{c m}^{2}\right)$ & $\mathrm{E}_{\mathrm{pa}}(\mathbf{V})$ & $\mathrm{j}_{\mathrm{pc}}\left(\mathbf{m A} / \mathbf{c m}^{2}\right)$ & $\mathrm{E}_{\mathrm{pc}}(\mathbf{V})$ & $\Delta \mathrm{E}_{\mathrm{p}}(\mathbf{V}){ }^{\text {(c) }}$ \\
\hline ARGF & 6.45 & 0.53 & 2.67 & 0.22 & 0.31 \\
\hline TTGF & 17.59 & 0.49 & 10.40 & 0.27 & 0.22 \\
\hline BiGF & 20.80 & 0.40 & 16.9 & 0.35 & 0.05 \\
\hline
\end{tabular}

(a) jpa: anodic peak current density

$\mathrm{E}_{\mathrm{pa}}$ : anodic peak potential

(b) $\mathrm{j}_{\mathrm{pc}}$ : cathodic peak current density

$E_{p c}$ : cathodic peak potential

(c) $\Delta E_{p}$ : peak potentials separation 


\section{Figure captions}

Figure 1. SEM images of the as-received (a), thermally treated (b) and (c) Bi-modified graphite felts. (d) Image of the Bi-modified felt obtained with a backscattering detector.

Figure 2. Cyclic voltammograms recorded in a $0.5 \mathrm{M} \mathrm{VOSO}_{4} / 1.0 \mathrm{M} \mathrm{H}_{2} \mathrm{SO}_{4}$ solution at a scan rate of $1 \mathrm{mVs}^{-1}$.

Figure 3. Cyclic voltammograms recorded on ARGF (a), TTGF (b) and BiGF (c) electrodes, in a $0.5 \mathrm{M} \mathrm{VOSO}_{4} / 1.0 \mathrm{M} \mathrm{H}_{2} \mathrm{SO}_{4}$ solution, at various scan rates. 

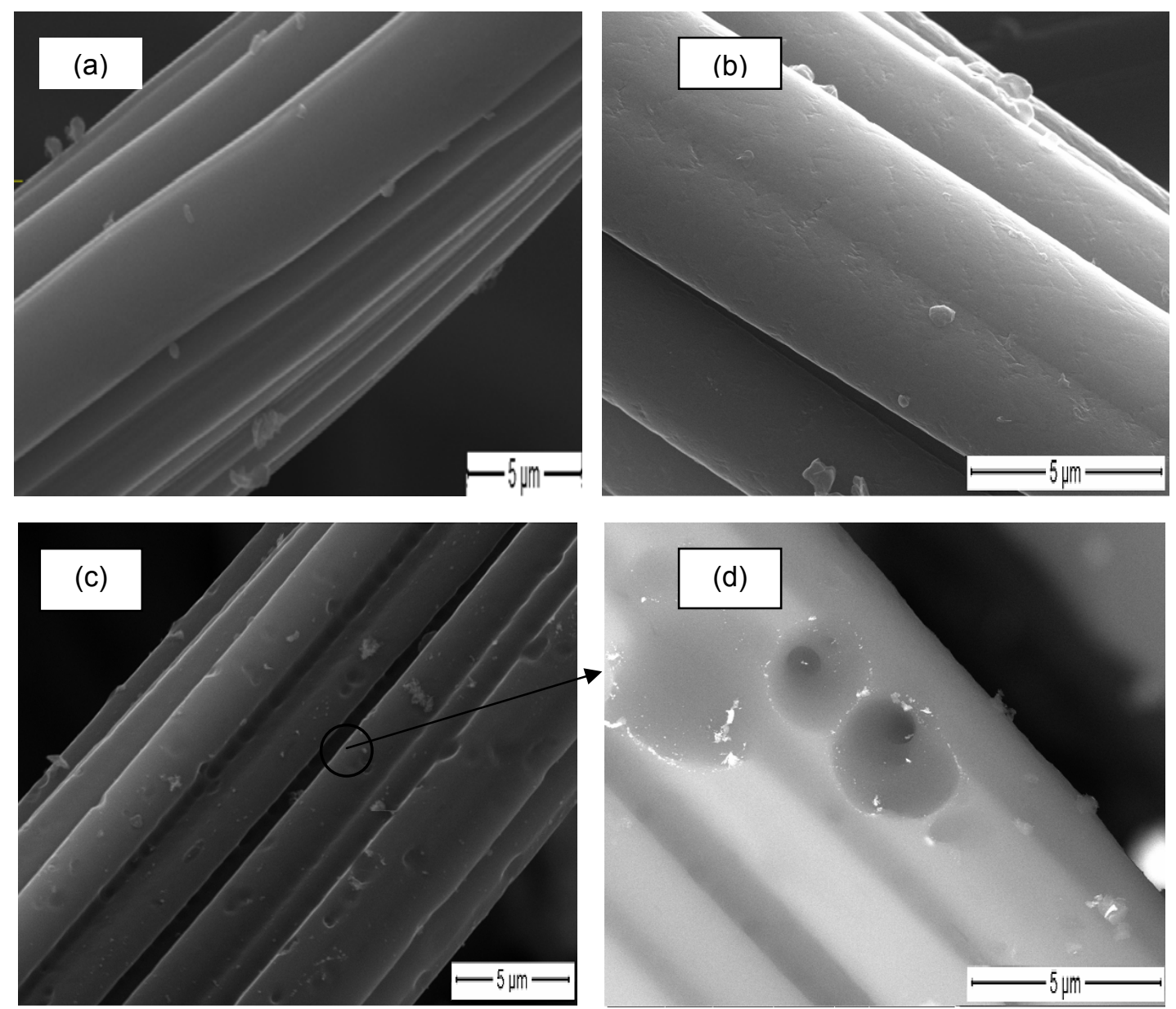

Figure 1. 


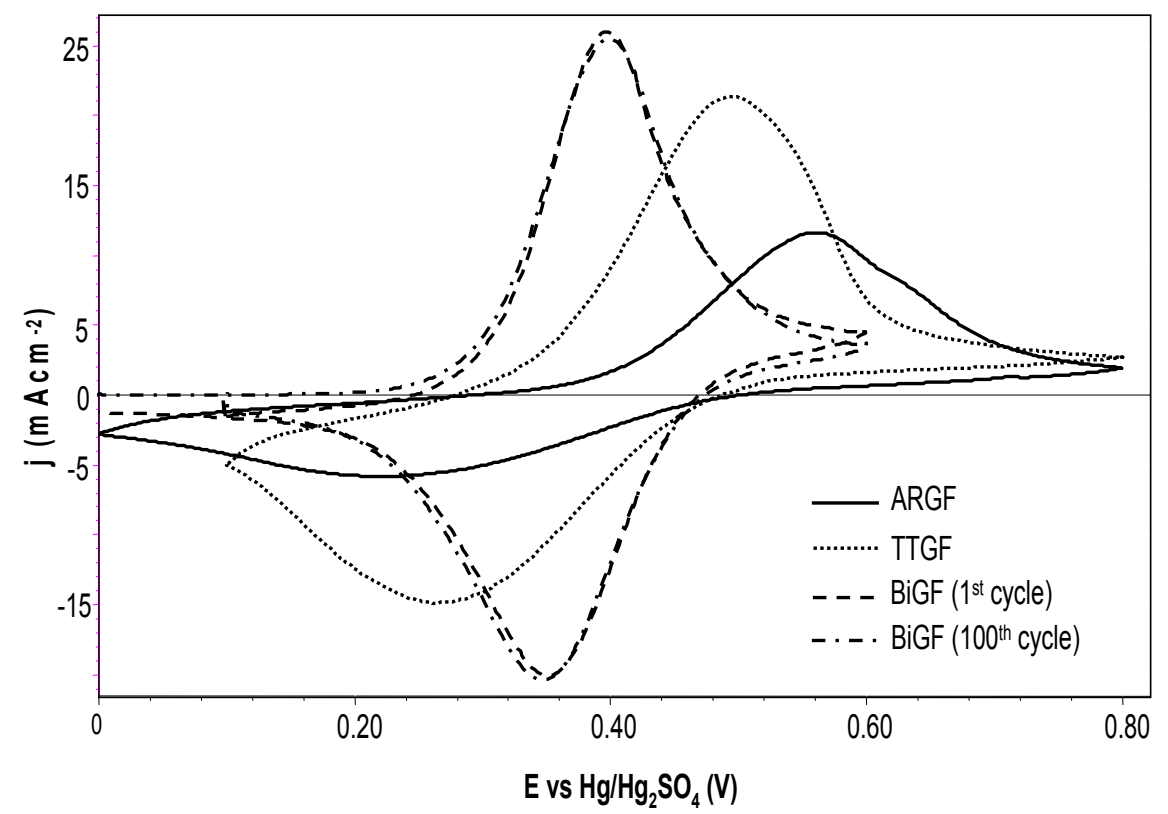

Figure 2. 

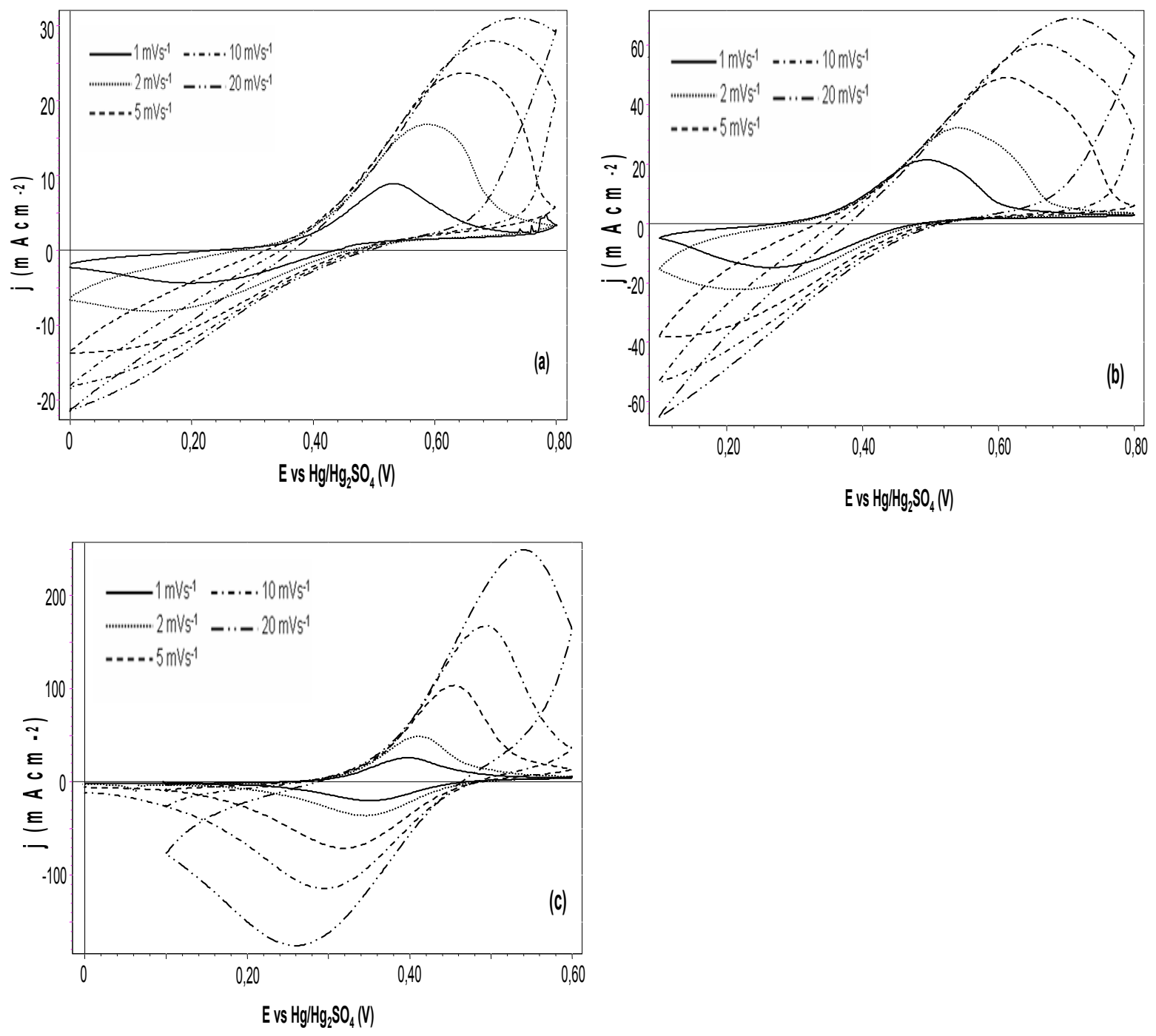

Figure 3. 